\title{
Honouring a life and narrative work: John's story
}

The proliferation of narrative work, cutting across disciplines and capturing a range of narrative approaches, with various analytical tools, methods and means, has generated an enormous and diverse body of scholarship (see, for example, Thornton, 1983, Charon, 2001, Czarniawska, 2004). How to make sense of, or include, 'broken' narratives, however, has received less attention (Hyden, 2008). The importance of witnessing broken narratives and somehow writing or representing these is matched by the challenges associated with trying to do this within a context of normativity and expected academic practice. As researchers and academics, we have to be convincing in our work, both in terms of rigour and dependability, but also in the way we make sense of the stories we are told.

Writing about ethnographic practice, Crapanzo (1986, p51) touches upon the issue of translating, or rendering the 'meaningless';

The ethnographer is a little like Hermes: a messenger who, given methodologies for uncovering the masked, the latent, the unconscious, may even obtain his message through stealth. He presents languages, cultures, and societies in all their opacity, their foreignness, their meaninglessness; then like the magician, the hermeneut, Hermes himself, he clarifies the opaque, renders the foreign familiar and gives meaning to the meaningless. He decodes the message. He interprets.

Giving 'meaning to the meaningless' through a process of 'magic' is a disconcerting statement, raising questions around whose 'meaning' and what role does the storyteller play in this translation, if any. For example, Amanda Baggs has demonstrated through film how her seemingly meaningless and repetitive actions (playing with the tap, shaking her hands, tapping the fridge door with a metal bangle) are actually her way of engaging in "constant conversation with every aspect of her environment". Without Baggs' interpretation, or translation, it is unlikely that a researcher 
would have been able to begin to understand and make sense of her world; we would simply 'not know'.

Those people who are not able to translate their narratives to a wider audience are, typically, shied away from in academia, not least because of the constraints around what is considered to be acceptable academic endeavour and outputs. Goodley and Moore (2001) highlight this difficulty in the context of disability research and disability politics, and the challenge of contradictory aims and values in trying to overcome the constraint of academic conventions. I suspect, nearly 16 years on, both authors would accept that this challenge remains.

I have come to realise over several years of generating, analysing and reading narrative accounts or analyses, or listening to work in progress by narrative scholars, that the human is sometimes lost in this endeavour. The narrated life (and being) can become obscured or sometimes erased by the careful application of the researcher's disciplinary knowledge and quest for coherent (and meaningful) narrative accounts. We stumble over words in our haste to make sense of narrative realities within our selected frameworks of understanding; sometimes coaxing, pushing or shoving analyses into predetermined (or desired) spaces, or cutting out, ignoring, or casually overlooking what is being said, or not said.

This could, in part, be related to the culture we live in, to modernity and a time of speed and distraction. As Back (2007, p7) argues, convincingly, 'we have become deaf not just to each other but also to the sounds all around us.' We have lost the skill of careful listening.

Reflecting on the research process, and this 'deafness', Back (2007, p17) suggests that 'Making the social world hold still for its portrait can seem like a gross violence, reducing its mutable flow to frozen moments preserved in the hoard frost of realist description.' (Back 2007, p17.) This portrait is, too often, presented via disembodied extracts of data, devoid of context and life. Back tells us about a participant who refused to conform to expected research interview rules and undermined the 
hierarchy between researcher and researched, in the process, helping the research team to face up to delusions around a democratised process. Back and his research team eventually 'fudged' the issue around analytic authority that the participant's disruption caused, bringing us back, again, to the tricky space of academic constraints and contradictory aims.

My thinking about this crystallised a year or so ago when I was doing a secondary analysis of a sample of narrative interviews generated by several researchers. My reanalysis was focusing upon the use of domiciliary care by people with long term conditions. During this analysis I became interested in how important pets were to many participants and yet, published findings of the research, both online at $\mathrm{xxxx}$ and in various journals, failed to mention pets. They were not considered to be of importance ( $\mathrm{xxxx}$ ). This was despite people talking about their pets with the same (or sometimes more) love and affection with which they talked about their children, their partners and other family members. To me, this neglect or dismissal could be described as a form of violence in not honouring the lives of our participants.

In the past, I've interviewed parents of autistic children and autistic adults. Autism is a spectrum condition and autistic people are a heterogeneous group of people. Whilst autism was originally considered to be a childhood condition, adults are increasingly being diagnosed. This raises fascinating conundrums around what it means to be 'autistic' and how people make sense of it. This meaning is continually evolving as a proliferation of 'autistic autobiographies' are published. These accounts offer an alternative reading to the accounts typically written by professionals which tend to objectify autistic people. One of the most well-known of this body of work is Donna William's Nobody Nowhere (1992), in which she describes how she lived in a 'world under glass' for over 25 years until she came across autism. The autistic label enabled her to make sense of the inner chaos and incomprehension she had lived with in her earlier life. Other, equally as absorbing, accounts 
include Lawson's Life behind Glass (2000) and Prince-Hughes Songs of the gorilla nation: My journey through autism (2004).

In addition to autobiographies, work by activists within the autistic community and qualitative researchers also challenge stereotypical representations, exclusionary practices and engage in identity politics. For example, Milton et al, (2012) directly call out the lack of autistic voices in the development of the Stony Brook Guidelines (Post et al, 2013) in a commentary highlighting paternalistic and disempowering practices. The lack of reciprocity around understanding differing ways of being is highlighted in Ryan and Raisanen's (2008) analysis of in-depth interviews with autistic adults, while Ortega and Choudhury (2011) explore the politics of 'neurological identities' through a comparative analysis of autistic people and adolescents. The autistic community in the UK (and wider) is effectively calling for the recognition of neurodiversity as a part of natural human diversity (Milton and MacLean, 2013) and being autistic has become an important identity for many.

Ian Hacking (1995) has contributed to this shifting understanding of autism with his concept of looping. This is where the diagnosed interacts with the diagnosis, looping back to modify the original diagnostic criteria. This is a process that can happen during a narrative interview when participants may make linkages or remould their stories and interpretations during the interview process (see, for example, Holstein and Gubrium, 1995). Hacking's work, focusing on the reflexive nature of autism, convincingly underlines the social construction of the autistic condition. Hacking describes how people are 'made up' through the process of science creating a kind, or type, of person that did not previously exist. He suggests that new or shifting categorisations 'alter the space of possibilities for personhood' and can 'change how we think of ourselves and change our sense of self-worth, even how we remember our own past' $(1995, \mathrm{p} 352,361,369)$. 
This altered space of possibilities (and arguably potential) is narrated through accounts generated by autistic people and through empirical research (see, for example, Davidson and Orsini, 2013). In the case of autism, where there is no clinical treatment and interventions are aimed at children rather than adults, getting a diagnosis of autism in adulthood can enable sense making both for the person gaining the label as well as those around them.

When interviewing people, I typically follow the approach Chamberlayne et al (2006) describe in their biographical interpretive narrative method. This involves a technique (or even revolution) of non-interruption (Jones, 2003); of encouraging people, through nodding or encouraging 'mmmm's', to narrate their experiences without further input or interruption from me beyond an initial question "Tell me your story..." It is not until this first part of the interview, which can last anything between a few minutes to nearly an hour, is ended by the participant that I start to ask further questions about what they have told me and then, finally, ask the questions I brought with me to the interview.

In this essay I consider one 'broken narrative' or perhaps, more accurately, a narrative I broke; John's story. The interview with John forms part of a larger dataset of interviews with autistic adults conducted 2007-2010. and video extracts from John's interview are available at xxxx. My analysis of this narrative involved reading, re-reading, thinking, noting, breaking up, making whole, breaking up and reading again. I initially focused on the stories within John's narrative; the stories John told about himself and those about people he knew; people who did well in life when he didn't think they necessarily should have done; and those who haven't, despite possessing what John sees as remarkable ability (which he sometimes but not always relates to autism). What emerged, through the process of analysis, and in particular by examining my interruptions to John's narrative, was my expectation and anticipation that John would tell a particular story. When he did not do this, I intervened to try to extract the story I thought existed; the story of diagnosis and subsequent sense 
making. Instead, John reflected on and used the interview space as a way of thinking about and making sense of his life and the challenges he experienced.

\section{John.}

I interviewed John in a hotel meeting room during a medical sociology conference in a city in the north of England. It was an unusually warm, early autumn day. The room faced the street and was noisy from traffic. John turned up looking very smart, wearing a suit and tie. It was clear from the start that he was a natural raconteur and took my invitation to tell me his story with some enjoyment. What was striking from the very start was that his narrative focused on his life generally - his school experiences, working life, travel, relationships and interests - and was not about autism.

Like Back's participant, this focus made visible the unrecognised illusions (or delusions) I had about my research. John's narrative was confounding my expectations of what an 'autism' narrative looked like. Why did that matter given I'd invited John to tell me his story? I knew, having conducted various secondary analyses, that an opening narrative is often interrupted by an impatient researcher wanting to get to the meat of what they are particularly interested in, or to keep participants 'on track'. These interruptions would make me wince when I came across them and I collected them to use in teaching research methods. The invitation to 'tell me your story' has a set of normative provisions attached to it which are not always apparent. These provisions are first, that there is a story to tell or extract and second, this story has to be framed in a particular, and unspoken way.

John talked for 21 minutes, largely about his school experiences (his ability to learn languages and his consistently poor mathematics) and his early work, before I broke my own interviewing rules by interrupting him and asking:

\section{So what made you go to the doctors?}


This clunky interruption which was unrelated to what John was talking about at that point demonstrates both the vague concern I had, that John did not actually fit the study criteria, and that I wanted to bring John back to what I expected (and wanted) to hear.

At that point John ignored my interruption and continued with his chronology of his working life:

What had happened was I had worked for quite a long time in [er] I worked in Amsterdam for seven years. I worked in London for a long time. I worked for [casino] as a croupier. So if you think it, it is quite a good job for somebody with Asperger's because [um] you need to be able to ignore everybody around you like you are particularly mad. Management are quite unbelievable. Casinos don't make money because they are well managed. They make money despite the fact that they are very badly managed and [um] again I got into that largely through a misunderstanding.

He occasionally mentioned autism in a very tangential way, for example in this extract, noting how a typical characteristic of Asperger syndrome - intense focus - is a useful skill in casino work. He had been a successful croupier for several years before he got caught up in a gambling scandal in the early 1980 s.

John continued, uninterrupted, for a further forty minutes until, as he talked about the police force in the town he lived being trained to better understand autistic people, I interrupted again with a second, unrelated, question:

\section{So what did you think when you actually received the diagnosis? Can you remember what you thought?}

We were 61 minutes into the interview and I still did not know if John was autistic. He responded to my question at this point and answered:

Well, relief! I thought that is it! When I first went over to the clinical psychologist he asked me a list of diagnostic questions. And [snaps fingers] somebody understands what I mean. 
Yes I do constantly misread people. I have got a habit, a long history of misreading people. Not knowing quite what people's motives are, unless it is very obvious, if it is absolutely blindingly obvious. You are doing research. You are a researcher. I am not. This is the roles, the roles are very clear. You know. It is when the roles ... at work, at work and this person is a manager or this person is the pit boss or whatever you know, this person is the designer, but it just gets vague, because it is not clearly defined.

John's narrative wove together a chronology of his life, stories about himself and others, and metareflections around being autistic or, more particularly, 'having Asperger syndrome'. He repeatedly returned to how he had always been good at French and English but failed in 'the business of people'. Diagnosed at the age of 60 and interviewed at 63, he picked over different points in his life, loosely exploring, sometimes implicitly, if his diagnosis helped him make sense of the consistent difficulties he had experienced. These difficulties I crudely lump together here as 'not getting life'. These involve an inability to imagine a future, being repeatedly taken advantage of, and not understanding sarcasm or other nuanced interactions.

My initial focus when trying to make sense of John's account was on the stories he told about himself and others, but after further reading, thinking and immersion in the data, the metareflections, woven throughout the interview, became more interesting. These reflections loosely involved reviewing his earlier life using the autistic lens he didn't have access to when he was growing up. As Hacking (2007, p303) says; 'In 1950 this was no way to be a person, people didn’t experience themselves in this way'. John had the tools within the interview setting to rethink and reform his experiences retrospectively:

I don't go crunching myself into books about it but from what I have read. I seem in many ways to be quite, I seem to have oh some, some at least of the characteristics that you would expect of someone with Asperger's. And then I began to feel, what about my age. I am not a child any more. Had I known years ago when I was 16 or 17, had somebody said me, "We 
think you are a bit special. We think you have got Asperger syndrome. Are you very good with languages?" Or, "Are you very good with detail? Do you collect things? Are you very good at collecting things? Collecting facts?" Collecting, like a train spotty mind if you want to put it that way.

This extract is again characteristic of the ambivalence John demonstrates about his diagnosis. He does not explicitly engage with an autistic identify, instead retaining some of his (authentic or essential) self. For example; 'I seem in many ways to be quite...' 'I seem to have, oh some, some at least of the characteristics you would expect of someone with Aspergers.' At the same time, he clearly recognises that his life could have been very different with a diagnosis:

And somebody younger, if that was assessed. If somebody younger was seen and assessed, screened and somebody would say well look don't do anything drastic, we will help you to make the most of it, to make the most of your life. And you will live a profitable and productive life and we are not going to mollycoddle you, but we will be there to keep an eye on you from afar as it were, you know, to make sure you are not going to get yourself into serious difficulties and my life would have been completely different. And I would like that to happen to younger people now. I really mean it. I really would. I know it sounds a lot possibly, but I don't think. I have thought about it. I mean, I said to you when you walked in here, before the camera was on, one of the things is, about this, people with Aspergers is we do pass for normal quite well.

Here John captures the support he would have liked; a safety net to prevent him getting into the serious difficulties he experienced across his life. At the end of this extract, he again demonstrates his ambivalence about autism. 'One of the things is, about this, people with Aspergers'. He follows this with 'we' but it again it appears he has not fully assumed an autistic identify. Unusually, in a qualitative interview, he explicitly calls me out as an actor in the production of his narrative. 'I said to you when you walked in here, before the camera was on', drawing attention to the behind the 
scenes aspects to qualitative research that do not tend to end up in the final, polished (researcher's) version.

After 30 years at work, which involved many mishaps and misunderstandings, John went back to university and studied 'Dutch and French'. He did very well but went on to reveal failings in his relationships and life more generally. Issues around drink and money management eventually led him to experience a breakdown, the introduction of social services into his life and, eventually, a diagnosis. As he said:

And [um] whatever I have got, and I knew it at the time, it was long before I was diagnosed. I don't have a learning disability. I have got people disability. I haven't got learning disability at all.

John clearly articulates that he knew for a long time that there was something different about him, something that interfered or disrupted his interactions with others. This extract offers some challenge to Hacking's argument that people are not being able to experience themselves as autistic before the condition was invented or constructed. John mentioned the revelatory aspect of being diagnosed as we saw earlier but, at the same time, he already 'knew'. At the end of the interview I asked John if there was anything else he wanted. Participants commonly say they can't think of anything at this stage, sometimes with self-prevaricating comments around having talked too much, or maybe remembering something later. It is an unusual experience to have a researcher intently probe into your experiences. John told me a lengthy story of his parents, a story he'd earlier said he wouldn't go into. He ended the interview as he began it; talking about his experiences at school:

But in the fifth form when everyone gets a prize, I got the school prize for French because I was simply the best. I was the best in the class and probably best in the school, at French and I won the school prize for Endeavour. I am good at trying. Well that is what I have 
been doing all my life. You know, I am still the same person, who was good at French and good at trying. And it has got me, where has it got me? You know, what am I? You know I am still wondering what to do. When you said to me how do you envisage the future, I mean I am still the same as I was when fifteen. I can't imagine the future. I wouldn't say I was stupid but there we are. Fifty years on. [laughs] Does any of that make sense?

John's story suggests the possibility or potential of transformation or re-narrativisation; a remaking or re-moulding of his narrative in light of new and previously unknown information. The space of possibilities for personhood has been widened by the identification or construction of a new type of person, following Hacking which, in turn, changes John's epistemic and moral relations with himself, including his self-concepts and self-worth. But John did know; as he said, 'And whatever I have got and I knew it at the time'.

John's narrative contains hope for other people; younger people who will now (he thinks) get the support he could not access. His narrative is different to many in the study. He doesn't embrace an autistic identity. He tries it on from time to time during the interview but never fully owns it. Revealingly, he does not seem to parcel life experiences into' autism related' explanations. Instead, autism seems to have a patchy, revelatory feel to it; it adds to the resources John has to make sense of his life experience. Furthermore, as Mattingly and others suggest; retellings of the story by the original narrator (and others) may eventually identify and enact strategies that create hope and resolve trouble, in the process changing both shared meanings and individual lives. This, relates to Hacking's concept of looping and has some relevance to John's interview, although I think the way he eventually ended the interview with the above extract (after nearly 2 hours) suggests little hope. At one point, he even thinks about whether his mother's post-partum depression and institutionalisation was somehow relevant to the difficulties he experienced. John's narrative is, overall, one of a life unfulfilled, loss and an undefined future. He remains wedded to who he is and always has been. As he says "I am still the same person". 
Researchers are not simply entrusted with broken narratives that need witnessing; we know we are active in the production and generation of these narratives. Narratives can be broken or silenced by the listener or the teller within the interview setting and by the researcher during the process of analysis and writing academic papers. Rigidity and too often uncreative or unimaginative, engagement by journal editors, peer reviewers and other academics, contribute to not 'honouring the stories of illness' (Charon, 2008) particularly when stories sit outside the expected or recognizable. This is concerning given broken narratives deserve greater attention and listening than those with coherence and a recognisable structure and content.

A year or so after interviewing John, I was working with a clinical colleague creating an e-learning package from the data generated by this project. She stuck her head around my office door one day and said, with considerable feeling, there was there was no way she could do my job. She had read John's transcript over lunch and found it boring. For her, John's narrative was, what Garro and Mattingley (2000) call a failed story; a story that leaves the audience wondering why it has been told. The failure is not to do with the structure of the story but the unanswered 'so what?' question. My colleague could not see the point to John's story. Her response to his unusual narrative, the intricate and complicated construction of it, and the way in which it did not conform to a typical narrative around diagnosis mirrored my concerns during the interview.

I have realised, through a careful examination of John's story, that I was not listening imaginatively during his interview. The research practice I prided myself on was a delusion. My interruptions to John's story reveal the assumptions and expectations I held. John used the interview setting to reflect on his life experiences and make sense of them in a broader way. It was a space for him to reflect on his experiences and to make connections between different parts of his life which may, or may not have been related to autism. He was making and remoulding his experiences, to the extent that, towards the end of the interview he talked about issues he earlier said he would not discuss. The process of revisiting John's interview and reanalysing the data has made me recognise that, in the same way that academic convention in research publications should be more flexible to allow 
engagement with broken narratives, I should have resisted, or ignored, the 'rules' of interviewing during this interview. John deserved a space to explore and make sense of his experiences beyond the tyranny of my research question. In effect, I was compounding the negative experiences he was recounting by trying to make him fit his story into a predefined template of what I thought a diagnosis story looks like.

I can imagine researchers countering this argument with 'but a research interview is not a therapeutic encounter' type argument. No, I agree, it isn't. But we have a duty to honour the lives of our participants and I think this duty is even stronger when the stories being told are about marginalisation and exclusion. We need to listen more carefully.

Back L (2007) The art of listening. Berg.

Baggs; https://www.youtube.com/watch?v=JnylM1hI2jc (accessed 16 February 2017)

Chamberlayne P, Bornat J and Wengraf T (2000). The turn to biographical methods in social science: Comparative issues and examples. Psychology Press.

Charon R (2001) Narrative medicine: a model for empathy, reflection, profession, and trust. Jama, 286(15), pp.1897-1902.

Charon R (2008) Narrative medicine: Honoring the stories of illness. Oxford University Press.

Crapanzano V (1986) Hermes' dilemma: The masking of subversion in ethnographic description. In: Clifford J and Marcus GE (eds) Writing culture: The poetics and politics of ethnography. University of California Press, pp.51-76.

Czarniawska B 2004. Narratives in social science research. Sage.

Davidson, J. and Orsini, M., 2013. The shifting horizons of autism online. Worlds of autism: Across the spectrum of neurological difference, pp.285-304. 
Garro LC and Mattingly C (2000) Narrative as construct and construction. In: Garro LC and Mattingly C (eds) Narrative and the cultural construction of illness and healing. University of California Press, pp.1-49.

Goodley D and Moore M (2000) Doing disability research: Activist lives and the academy. Disability \& Society 15(6):861-882.

Hacking I (1995) The looping effects of human kinds. In: Sperber D, Premack D and Premack A. Causal cognition: A multidisciplinary debate. Oxford: Clarendon Press, pp.351-394.

Holstein JA and Gubrium JF (1995) The active interview (Vol. 37). Sage.

Hydén LC (2008) Health, Culture and Illness. In: LC Hydén and J Brockmeier (eds) Broken Narratives New York: Routledge, pp36-53.

Jones K (2003) The turn to a narrative knowing of persons: One method explored. NT Research, 8(1):60-71.

Lawson W (2000) Life behind glass: A personal account of autism spectrum disorder. Jessica Kingsley Publishers.

Milton, D., Mills, R. and Pellicano, L., 2012. Ethics and autism: where is the autistic voice?

Commentary on Post et al. Journal of autism and developmental disorders, 44(10), pp.2650-2651.

Milton, Damian Elgin Maclean. "'Filling in the Gaps’: A Micro-Sociological Analysis of Autism." Autonomy, the Critical Journal of Interdisciplinary Autism Studies 1.2 (2013).

Ortega, F. and Choudhury, S., 2011. 'Wired up differently': Autism, adolescence and the politics of neurological identities. Subjectivity, 4(3), pp.323-345.

Post, S.G., Pomeroy, J., Keirns, C.C., Cover, V.I., Dorn, M.L., Boroson, L., Boroson, F., Coulehan, A., Coulehan, J., Covell, K. and Kubasek, K. (2013) Brief report: Stony Brook Guidelines on the 
ethics of the care of people with autism and their families. Journal of autism and developmental disorders, 43(6), pp.1473-1476.

Prince-Hughes D (2004) Songs of the Gorilla Nation ed. New York: Harmony.

Ryan S and Räisänen U (2008) "It's like you are just a spectator in this thing”: Experiencing social life the 'aspie'way. Emotion, space and society, 1(2), pp.135-143.

Thornton R 1983. Narrative ethnography in Africa, 1850-1920: the creation and capture of an appropriate domain for anthropology. Man, pp.502-520.

Williams D (1992) Nobody nowhere: The remarkable autobiography of an autistic girl. London: Jessica Kingsley.

(xxxxx) 